\title{
Maxillofacial Injuries due to Motorcycle Accidents Caused by Stray Animals: An Etiology 'Kept Out Of Sight': A Report of 5 Cases
}

\author{
D.S. Thalakiriyawa, BDS ${ }^{*} \mathbb{D}$, R.M.S.H.B Medawela BDS ${ }^{1} \mathbb{D}$, W.M.S.N.Weerasinghe \\ $B D S^{2}$, S.A.K.J. Kumara BDS, $M^{3}$ and N.S.S. Jayasuriya BDS, $M^{1}$
}

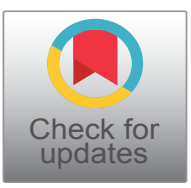

${ }^{1}$ Faculty of Dental Sciences, University of Peradeniya, Peradeniya, Sri Lanka

${ }^{2}$ National Dental Teaching Hospital, Colombo, Sri Lanka

${ }^{3}$ District General Hospital, Gampaha, Sri Lanka

*Corresponding author: Dr. DS Thalakiriyawa, BDS, Faculty of Dental Sciences, University of Peradeniya, Peradeniya, Sri Lanka, Tel: 00-94-714753123

\begin{abstract}
The oral and maxillofacial region occupies the most prominent position of the human body rendering it vulnerable to injuries quite frequently. These injuries are commonly associated with high morbidity resulting in increased costs of care and varying degrees of physical, functional, and cosmetic disfigurement. Multiple etiologies of oral and maxillofacial trauma include road traffic accidents, falls, assaults, industrial injuries etc. out of which road traffic accidents is the commonest etiology in many regions across the globe. Among these, road traffic accidents caused due to stray animals remains an undisclosed and a scarcely documented issue. The Current case series highlights five cases of maxillofacial injuries presented to Oral and Maxillofacial Surgery Unit, District General Hospital Gampaha, Sri Lanka within a short span of time following road traffic accidents associated with stray animals.
\end{abstract}

\section{Keywords}

Maxillofacial trauma, Stray animals, Road traffic accidents

\section{Abbreviations}

OMF: Oral and Maxillofacial; RTA: Road Traffic Accidents; AVC: Animal-Vehicle Collision; CRIS: Clinical Record Interactive Search; WHO: World Health Organization

\section{Introduction}

The etiology of maxillofacial injuries varies from one country to another and even within the same country depending on the prevailing socioeconomic, cultural, and environmental factors. Common causes of Oral and Maxillofacial (OMF) trauma include road traffic accidents (RTA), falls, assaults, sports and work injuries with RTA on the lead in many regions of the world except in some European countries where assaults and falls are the commonest causes $[1,2]$.

RTA are one of the major causes of morbidity and mortality of which victims may succumb to multiple serious injuries including maxillofacial injuries. Within the category of traffic accidents, bicycle and motorcycle accidents deserve special significance as they play a substantial role in the etiology of maxillofacial trauma [3].

According to the Global status report of Road safety 2018 launched by the World Health Organization (WHO), the number of deaths caused by RTA is approximately 1.35 million per year with nearly 15-20 million people injured [4]. The incidence of RTA are on the rise due to increasing numbers of vehicles, lack of road infrastructure, lack of discipline on the road including driving under the influence of alcohol [5]. The situation remains no different in Sri Lanka. According to the latest WHO data published in 2018 , deaths caused due to RTA have reached 3,554 or $2.80 \%$ of total deaths in Sri Lanka [6]. Currently, there is very limited data available

Citation: Thalakiriyawa DS, Medawela RMSHB, Weerasinghe WMSN, Kumara SAKJ, Jayasuriya NSS (2020) Maxillofacial Injuries due to Motorcycle Accidents Caused by Stray Animals: An Etiology 'Kept Out Of Sight': A Report of 5 Cases. Trauma Cases Rev 6:086. doi.org/10.23937/2469-5777/1510086 Accepted: December 29, 2020: Published: December 31, 2020

Copyright: (C) 2020 Thalakiriyawa DS, et al. This is an open-access article distributed under the terms of the Creative Commons Attribution License, which permits unrestricted use, distribution, and reproduction in any medium, provided the original author and source are credited. 
Table 1: Details of the cases.

\begin{tabular}{|l|l|l|l|l|}
\hline Age/Gender & Mode of travel & $\begin{array}{l}\text { Animal involved and } \\
\text { injuries to animal }\end{array}$ & Injuries to the rider & Type of road \\
\hline 26 Male & Motorcycle & Stray dog: No injuries & $\begin{array}{l}\text { Soft tissue lacerations } \\
\text { Dento-alveolar injuries }\end{array}$ & Side road \\
\hline 34 Male & Motorcycle & Cow: No injuries & $\begin{array}{l}\text { Soft tissue lacerations } \\
\text { Dento-alveolar injuries }\end{array}$ & Side road \\
\hline 35 Male & Motorcycle & $\begin{array}{l}\text { Stray dog: Visible injury with } \\
\text { limping }\end{array}$ & $\begin{array}{l}\text { Soft tissue lacerations } \\
\text { Mandibular fractures }\end{array}$ & Main road \\
\hline 50 Male & Motorcycle & Stray dog: Has not hit the dog & Soft tissue lacerations & Side road \\
\hline 29 Male & Motorcycle & Stray dog: Has not hit the dog & Soft tissue lacerations \\
Mandibular fractures & Main road & \\
\hline
\end{tabular}

on the percentage of trauma involving the OMF region. Among the few reports done on OMF trauma in Sri Lanka a study done in 1988 revealed, fall from height as the commonest cause of mandibular fractures in children in Sri Lanka [7]. A recent update on the etiology of OMF trauma has not been documented. However, RTA can be deduced as the commonest cause of OMF trauma in Sri Lanka as of today.

Among the many factors that are responsible for RTA, animal-vehicle collision (AVC) remains an under described and an unrecognized etiology which is on the rise due to increasing traffic intensities coinciding with wildlife habitats [8] Even though this is deemed to be responsible for a significant percentage of OMF trauma globally, this can be relatively more common in certain geographical areas. It is reported that nearly 200 people, often motorcyclists lose their lives on U.S roadways each year from collisions involving wild or domestic animals, and thousands more are seriously injured [6]. Also, An Australian study conducted Between 2007 and 2016 revealed, that $1.5 \%$ of the major trauma cases due to RTA were due to animal-related crashes [9]. An Indian study revealed that the most common etiology for OMF trauma is RTA (78\%) especially involving two-wheelers. This was further documented to be either due to self fall from bikes caused by an inability to control the speed due to poorly built roads or colliding with animals such as stray dogs and cattle [10]. However, it was found in a study carried out in Brazil in 2011 that accidents involving animals were relatively more common in rural areas [3].

In Sri Lanka, where the incidence of RTA is extremely high, a significant percentage of OMF trauma may be caused due to AVC irrespective of the geographical location, even though those cases may not be recognized or reported. The animal species that are frequently involved in AVC may include dogs, cattle and birds such as peacocks. Two or three-wheeled vehicles are a common mode of transport in developing countries such as India and Sri Lanka. These vehicles are often being encountered in such accidents and carry an inherent potential of being left with detrimental injuries.
The facts that motorcyclists and bicycle drivers are more susceptible to maxillofacial injuries and that they're more prone to relatively more serious injuries sustained due to AVC have been revealed in multiple studies $[9,10]$ Therefore, the postulation that AVC could frequently give rise to OMF trauma cannot be dismissed. Hence it is important to identify AVC as an emerging etiology of OMF trauma and spread awareness and implement strategies to mitigate the occurrence of these injuries.

The current report is an effort of documenting a unique series of 5 cases of OMF trauma caused due to animal-vehicle collisions presented to District General Hospital Gampaha, Sri Lanka within a short span of time.

\section{Summary of Case Reports}

All five patients were young adult males who were riding a motorcycle at night. All patients were under the influence of alcohol at the time of injury except for case 1 , all others had been travelling over the designated speed limit (Table 1).

\section{Discussion}

Maxillofacial trauma poses serious challenges to every stratum in the trauma management team from the primary caregiver to an oral and maxillofacial surgeon. A certain proportion of maxillofacial injuries are complex [11]. Being the most uncovered and unprotected part of the body, the face is particularly more susceptible to trauma [5]. Contrarily, injuries to the maxillofacial region may also lead to a number of detrimental outputs especially since it is the region of specialized functions such as vision, hearing, olfaction, respiration, mastication and speech that consists of vital vascular and neural structures $[12,13]$. Therefore, OMF trauma can be considered a huge health hazard and an enormous social and economic burden. However, the pattern of injury sustained by the maxillofacial region greatly depends on the etiology and nature of the impact [14].

AVC are an unidentified etiology of OMF trauma all over the world. As brought into light in the above series 
of cases these can give rise to multiple non-fatal but disfiguring and debilitating injuries.

AVC can be classified into two as direct and Indirect collisions. A direct collision is when the vehicle directly hits the animal and results in either the animal being thrown to a side, vehicle running over the animal or the animal getting thrown in the air following the collision and falling on the windshield out of which the third could result in more critical injuries to the driver of the vehicle and the animal. The outcome of direct collisions may depend on the speed of the vehicle and the speed of the incoming or outgoing animal. An indirect collision is when an accident occurs because the driver of one vehicle changes the direction of his driving trying to avoid the animal and hits another vehicle, person or road infrastructure, or gets overturned $[11,15]$.

Previous studies claim that less than $62 \%$ of animal-related crashes do not involve the vehicle striking an animal, but rather the vehicle swerving to avoid an animal and resulting in another subsequent action However, $68.8 \%$ of the fatal crashes were attributable to direct collisions $[16,17]$.

A Spanish study conducted in 2018 revealed that most AVC involve domestic animals (>95\%), particularly dogs (> 80\%). This pattern contrasts with that of some other regions of Spain and European regions, where collisions are mostly caused by game species [8]. In the present case series 4 out of the 5 accidents involved collision with dogs. Reports estimate that the Gampaha district where the cases were reported has a dog to human ratio of 1:4 [18].

All five of the above cases involved motorbikes. Based on observations from the Clinical Record Interactive Search (CRIS) data during the years 2010-2016 motorcycles comprised only 2.2-3.5\% of total reported AVCs, yet accounted for at least half of all fatal or injurious crashes [19]. These animal-motorcycle collisions are particularly injurious, as motorcycles are two-wheeled single-track vehicles that lack lateral stability when stationary. In addition, the driver has no physical protection between himself and the animal except for a helmet in which's presence OMF trauma can still be inevitable [9].

A study conducted in the U.S. from 1995 to 2004 revealed that $89.5 \%$ of fatal AVC occurred on rural roads, $85.4 \%$ on straight sections of road, $91.1 \%$ occurred in dry weather conditions, and $28 \%$ of the victims were motorcyclists. A large proportion of injuries from AVC in the U.S. involved deer $[17,20]$.

The above study also highlighted that $64.8 \%$ of the AVC occurred in darkness which was also emphasized as a major risk factor in several other studies. Most AVCs (71\%) occurred at night in unlit locations. Reported crash frequencies were also much higher in dark settings [9].
All of the patients discussed in the present case series were under the influence of alcohol when they met with the accidents. Alcohol can affect a driver's cognition, vigilance, attention, reaction, judgment and especially distance and depth perception which are closely related to driving ability. Even at low doses, alcohol can significantly affect driving-related skills such as vision, braking behavior, and vigilance [21]. At the same time, drivers' information process and attention are heavily affected by alcohol. Therefore, in the case of a sudden obstacle such as an animal, the action of instantly acting to avoid the obstacle cannot be anticipated from a driver who is under the influence of alcohol.

Evasive behavior of animals is one of the major factors associated with AVCs. An animal that suddenly encounters an oncoming vehicle is likely to rely on its antipredator behavioral actions to face the situation. For example, moving away from the line of the vehicle's travel will be an effective evasive response in most cases.

However, this response may not be observed in all species. Several species might respond to an oncoming vehicle by freezing to avoid detection as they would do in the face of a predator. This can lead to definite indirect or direct collisions depending on the driver's reaction. Species with inappropriate or ineffective defensive responses are more likely to be greatly affected by road associated mortality [22]. Hence, it is important to make drivers aware of these behaviors and instant actions and techniques that would aid in minimizing the magnitude of these accidents.

Even though it is underreported AVC remains an important etiological factor of RTA leading to OMF trauma. The present study aims to address the knowledge gap and draw attention to implementing preventive strategies such as introducing speed limits to areas where a high risk of AVC prevail and also instate road infrastructure such as roadway lighting, fences and road rails to avoid animals crossing the road from potentially dangerous locations such as steep hills and bends and straight sections of road. Moreover, behavioral strategies such as spaying and neutering domestic animals can also be implemented to minimize the count of stray animals. Further, with the use of the continuously developing technology, digital Animal detection systems which are currently being developed can be expected to be seen in modern vehicles in near future [15]. Nevertheless, a continuing audit of the etiology of OMF trauma is mandatory as it reflects the effectiveness of the existing preventive strategies and would also act as an important indicator that would aid in changing resource and training needs in oral and maxillofacial surgery [23].

\section{Conclusion}

AVC are a rising etiology for OMF trauma that is unrecognized and in 'hindsight'. The current case reports highlight that motorcyclists travelling over the speed 
limit with intoxication by alcohol are more prone to encounter stray animals and sustain injuries from a fall. More detailed studies and education of riders will help to alleviate the problem.

\section{Acknowledgement}

\section{Funding}

None.

\section{Conflicts of interest/Competing interests}

None.

\section{Ethical clearance}

Not applicable.

\section{Patient consent}

Patients' consents have been obtained.

\section{References}

1. Naveen Shankar A, Naveen Shankar V, Hegde N, Sharma, Prasad R (2012) The pattern of the maxillofacial fractures A multicenter retrospective study. J Craniomaxillofac Surg 40: $675-679$.

2. Boffano $P$, Roccia $F$, Zavattero $E$, Dediol E, Uglešić $V$, et al (2015) European Maxillofacial Trauma (EURMAT) project: A multicentre and prospective study. J Craniomaxillofac Surg 43: 62-70.

3. Batista Anne Margareth, Marques Leandro Silva, Batista Aline Elizabeth, Falci Saulo Gabriel Moreira, Ramos-Jorge Maria Letícia (2012) Urban-rural differences in oral and maxillofacial trauma. Brazilian Oral Research 26: 132-138.

4. World Health Organization (2018) Global status report on road. World Health Organization, 2018.

5. Agnihotri A, Galfat D, Agnihotri D (2014) Incidence and pattern of maxillofacial trauma due to road traffic accidents: A prospective study. J Maxillofac Oral Surg 13: 184-188.

6. WHO (2018) World health statistics 2018: Monitoring health for the SDGs, World Health Organization, Geneva.

7. Amaratunga NA (1988) Mandibular fractures in children--a study of clinical aspects, treatment needs, and complications. J Oral Maxillofac Surg 46: 637-640.

8. Canal D, Martín B, De Lucas M, Ferrer M (2018) Dogs are the main species involved in animal vehicle collisions in southern Spain: Daily, seasonal and spatial analyses of collisions. PLoS One 13: e0203693.

9. Donaldson B, Lafon N (2008) Testing an integrated PDAGPS system to collect standardized animal. Carcass removal data.
10. Ang JY, Gabbe B, Cameron P, Beck B (2019) Animal-vehicle collisions in Victoria, Australia: An under-recognised cause of road traffic crashes. Emerg Med Australas 31: 851-855.

11. Anitha R, Devakumari S (2017) Prevalence and patterns of maxillofacial trauma in South India-a retrospective study for seven years. Journal of Dental and Medical Sciences 16: 22-25.

12. Majambo M, Sasi R, Mumena C, Museminari G, Nzamukosha J, et al. (2013) Prevalence of oral and maxillofacial injuries among patients managed at a teaching hospital in rwanda. Rwanda Journal of Health Sciences 2: 20.

13. Shahim F, Cameron $P$, McNeil J (2006) Maxillofacial trauma in major trauma patients. Aust Dent J 51: 225-230.

14. Pappachan B, Alexander M (2012) Biomechanics of cranio-maxillofacial trauma. J Maxillofac Oral Surg 11: 224230.

15. Sharma SU, Shah DJ (2016) A practical animal detection and collision avoidance system using computer vision technique. IEEE 5: 347-358.

16. Rowden Peter, Steinhardt Dale, Sheehan Mary (2008) Road crashes involving animals in Australia. Accident Analysis and Prevention 40: 1865-1871.

17. Conn JM, Annest JL, Dellinger A (2004) Nonfatal motor-vehicle animal crash-related injuries - United States, 2001-2002. Journal of Safety Research 35: 571-574.

18. Pimburage RMS, Harischandra PAL, Gunatilake M, Jayasinhe DN, Balasuriya A, et al. (2017) A cross-sectional survey on dog ecology and dog anti-rabies vaccination coverage in selected areas in Sri Lanka.

19. Wilkins DC, Kockelman KM, Jiang N (2019) Animal-vehicle collisions in Texas: How to protect travelers and animals on roadways. Accident Analysis \& Prevention 131: 157-170.

20. Langley RL, Higgins SA, Herrin KB (2006) Risk factors associated with fatal animal-vehicle collisions in the United States, 1995-2004. Wilderness Environ Med 17: 229-239.

21. Zhao X, Zhang X, Rong J (2014) Study of the effects of alcohol on drivers and driving performance on straight road. Mathematical Problems in Engineering, 2014.

22. Fahrig, Lenore, Trina Rytwinski (2009) Effects of roads on animal abundance: An empirical review and synthesis. Ecology and Society 14: 21.

23. Gupta A, Babu AK, Bansal P, Sharma R, Sharma SD (2018) Changing trends in maxillofacial trauma: A 15 years retrospective study in the Southern Part of Haryana, India. Indian J Dent Res 29: 190-195. 